Article

\title{
Reactive High-Power Impulse Magnetron Sputtering of Chromium-Carbon Films
}

\author{
Chin-Chiuan Kuo ${ }^{1, *}$, Chun-Hui Lin ${ }^{1}$, Jing-Tang Chang ${ }^{2}$ and Yu-Tse Lin ${ }^{2}$ \\ 1 Department of Mechanical and Computer Aided Engineering, National Formosa University, \\ Huwei, Yunlin County 63201, Taiwan; 10920110@gm.nfu.edu.tw \\ 2 Coating Department, Supati Corporation, Citong, Yunlin County 64747, Taiwan; \\ jingtangc@gmail.com (J.-T.C.); d0875102@gm.nfu.edu.tw (Y.-T.L.) \\ * Correspondence: cckuo@nfu.edu.tw; Tel.: +886-5631-3492
}

Received: 30 November 2020; Accepted: 18 December 2020; Published: 21 December 2020

check for updates

\begin{abstract}
Chromium-carbon films were deposited by utilizing reactive high-power impulse magnetron sputtering at different mixture ratios of ethyne and argon atmosphere, and different substrate bias voltages and deposition temperature, with the same pulse frequency, duty cycle, and average power. The microstructure and mechanical properties of the obtained films were compared. The films consist of amorphous or nanocrystalline chromium carbide, hydrogenated amorphous carbon, and minor $\alpha$-chromium phase. Decreasing the fraction of ethyne increases the content of the $\alpha$-chromium phase but decreases hydrogenated amorphous carbon phase. The film's hardness increases by enhancing the negative substrate bias and raising the deposition temperature, which could be attributed to the increase of film density and the Hall-Petch strengthening effect induced by the nanoscale crystallization of the amorphous carbide phase.
\end{abstract}

Keywords: chromium carbide; hydrogenated amorphous carbon; high-power impulse magnetron sputtering

\section{Introduction}

The combination of chromium and carbon can synthesize various compounds, including metallic alloy, chromium carbides of different stoichiometric compositions, and carbon-based materials, which show different hardness, toughness, chemical stability, electrical conductivity, and tribological properties [1-8]. Metal-carbon thin films are easily synthesized via plasma-enhanced physical vapor depositions, such as cathodic arc ion plating [5,6,9], magnetron sputtering [10-15], electron-beam deposition [16,17], high-power impulse magnetron sputtering [12,18-20], and a hybrid method [21]. The hardness of chromium carbide is varied up to ten times depending on the deposition processes [13-15]. Therefore, carbide coatings are commonly used as an adhesion enhancement interlayer between metallic workpieces and an amorphous carbon topcoat [21,22]. The mechanisms of hardness enhancement for these carbides and carbon-based coatings are due to their nanocomposite structure. These coatings typically consist of an amorphous carbon (hydrogenated diamond-like or graphite-like a-C:H phase) and a crystalline metal or hard metal carbide phase [15,23]. The fractions of $s p 3 / s p 2$ bonding ratio and nanocrystalline carbide phases influence the hardness, elastic modulus, and thermal stability of coatings $[15,24]$. The ratio of a-C:H and carbide phases is usually dominated by the mixture ratio of hydrocarbon and inert gas during the deposition [5-22], and the $s p 3 / s p 2$ bonding ratio of a-C:H phases and grain size of carbides are strongly affected by the substrate bias voltage and the pulse width $[6,14,18,19]$.

High-power impulse magnetron sputtering (HiPIMS) provides high power densities in pulses with a low duty cycle $[25,26]$ on a magnetron sputtering source cathode, which enables high-density plasma 
waves and fluxes of ionized sputtered source materials. This benefits the alteration of the kinetic energy of incident ions and the migration of adatoms through controlling substrate biasing and the pulse power density, which results in the variety of the microstructure, hardness, and adhesion of the obtained coatings [27-31]. However, the reactive HiPIMS deposition is much more complex [26]. Preventing the target poisoning and the consequent arc discharge on the source target restricts the region of the applied pulse width on the source target. Furthermore, applying a direct current high substrate bias voltage may result in the charging and arcing on a non-conductive compound coating [26,32], which also limits the region of substrate biasing. A pulsed substrate bias can effectively prevent this disadvantage [32], and increases the film density in the HiPIMS process [26,33]. Although the reactive sputter deposition of $\mathrm{Cr}-\mathrm{C}$ films has been widely researched, the applications of the reactive HiPIMS deposition of such materials are still rare [20], and the usage of synchronized pulsed substrate bias is not reported in these articles. In this work, various $\mathrm{Cr}-\mathrm{C}$ films were prepared using the HiPIMS technique, by introducing different mixture ratios of argon and ethyne and applying different synchronized pulsed substrate biases and different deposition temperatures for comparison.

\section{Materials and Methods}

The $\mathrm{Cr}-\mathrm{C}$ films were deposited in a vacuum chamber with one unipolar HiPIMS power and one unipolar substrate bias power. The details of the power supplies, the target, the size of substrate samples, and the cleaning of substrate samples can be found in our previous work of chromium film [31]. Three different substrate materials had been polished and were simultaneously used, including an AISI M35 high-speed steel disc with a size of $\phi 30 \times 1(h) \mathrm{mm}^{2}$, a SUS 304 stainless steel mirror plate, and silicon wafer chips. After placing samples into the deposition chamber, vacuuming, and cleaning with argon plasma, the substrate temperature raised to about $190^{\circ} \mathrm{C}$ without using additional substrate heating. For a higher deposition temperature, of $300^{\circ} \mathrm{C}$, the additional substrate heating would be applied during the argon plasma cleaning. The deposition parameters for $\mathrm{Cr}-\mathrm{C}$ films are shown in Table 1.

Table 1. Parameters for the deposition of chromium-carbon films.

\begin{tabular}{ccc}
\hline \multicolumn{2}{c}{ Deposition Parameters } & Value \\
\hline \multirow{2}{*}{ Atmosphere } & Pressure $(\mathrm{Pa})$ & 0.8 \\
& $\mathrm{Ar} / \mathrm{C}_{2} \mathrm{H}_{2}$ flow ratio & $1: 1,6: 1,8: 1,12: 1$ \\
\hline \multirow{2}{*}{ Target HiPIMS power } & Average power $(\mathrm{kW})$ & 3 \\
& Peak voltage $(\mathrm{V})$ & $-518 \sim-612$ \\
& Peak current $(\mathrm{A})$ & $254 \sim 199$ \\
& Pulse frequency $(\mathrm{Hz})$ & 332 \\
Cr ion bombardment & Pulse width $(\mu \mathrm{s})$ & 60 (duty cycle $2 \%)$ \\
\hline \multirow{2}{*}{$\mathrm{Cr}-\mathrm{C}$ film deposition } & Synchronized bias voltage pulse & $-1000 \mathrm{~V}$ (pulse width $96 \mu \mathrm{s})$ \\
& Bombardment time & $40 \mathrm{~s}$ \\
\hline Deposition temperature $\left({ }^{\circ} \mathrm{C}\right)$ & Ground $0 \mathrm{~V}$, \\
& Notes: high-power impulse magnetron sputtering (HiPIMS).
\end{tabular}

Different mixture ratios of argon/ethyne-1:1, 6:1, 8:1, 12:1—were respectively introduced to keep a deposition pressure $0.8 \mathrm{~Pa}$ for $\mathrm{Cr}-\mathrm{C}$ film depositions. The applied target HiPIMS voltage pulses were near to a rectangle shape with a width of $60 \mu \mathrm{s}$ and a frequency of $332 \mathrm{~Hz}$. The pulse voltage and corresponding peak current on the target floated between -518 to $-612 \mathrm{~V}$ due to the varying target conditions and the set deposition atmosphere. The pulse frequencies were manually set with the same pulse duty cycle, $2.5 \%$, to maintain a constant target average power at $3 \mathrm{~kW}$ for all depositions.

As reported in the previous work [31], applying a pulsed substrate bias synchronized with the HiPIMS discharge pulse is helpful to selectively attract ions and the charged species with a stable bias 
voltage and enable the target ion bombardment for a stronger film adhesion. The $\mathrm{Cr}$ ion bombardment was carried out before the $\mathrm{Cr}-\mathrm{C}$ layer deposition. As the target HiPIMS pulse began, the substrate bias voltage pulse of $-1000 \mathrm{~V}$ with a 1.75 -fold pulse width of HiPIMS pulses was simultaneously initiated in order to accelerate $\mathrm{Cr}$ ions to bombard on the substrate. To minimize the roughness and temperature change on the substrate surface, the $\mathrm{Cr}$ ion bombardment was restricted to $40 \mathrm{~s}$. After the bombardment, the substrate bias voltage switched to $0 \mathrm{~V}$ (grounded), pulsed $-60 \mathrm{~V}$, or pulsed $-150 \mathrm{~V}$ directly without any gradient substrate biasing, to deposit different $\mathrm{Cr}-\mathrm{C}$ films.

The microstructures of deposited films are observed by using a scanning electron microscope (SEM, S-4800 Cold Field Emission Scanning Electron Microscope, Hitachi, Tokyo, Japan). The film's thickness was estimated from cross-sectional SEM micrographs, and the crystallinity was characterized by utilizing an X-ray diffractometer (D8 Discover X-ray diffractometer, Bruker, Billerica, MA, USA). A Raman spectrometer (PROTRUSTECH, Tainan, Taiwan) was used to determine the presence of oxide and carbon phases in the $\mathrm{Cr}-\mathrm{C}$ films. The nanoindentations (A TTX-NH3 nanoindentation tester, Anton Paar, Graz, Austria) were carried out to evaluate the film's hardness. Settings of analysis instruments were as the same as described in the references [30,31].

\section{Results and Discussion}

\subsection{The Influences of Different $\mathrm{Ar} / \mathrm{C}_{2} \mathrm{H}_{2}$ Flow Ratios}

The Raman spectra of the $\mathrm{Cr}-\mathrm{C}$ films deposited at different $\mathrm{Ar} / \mathrm{C}_{2} \mathrm{H}_{2}$ flow ratios and the pressure of $0.8 \mathrm{~Pa}$ for $10 \mathrm{~min}$ are shown in Figure 1. Only two major peaks, the $\mathrm{G}\left(\sim 1580 \mathrm{~cm}^{-1}\right)$ and $\mathrm{D}\left(\sim 1350 \mathrm{~cm}^{-1}\right)$ bands of carbon phases, and a minor peak of $\mathrm{Cr}_{2} \mathrm{O}_{3}\left(\sim 541 \mathrm{~cm}^{-1}\right)$ phase can be identified. The peaks of chromium carbides are very weak. This indicates that the microstructure of deposited $\mathrm{Cr}-\mathrm{C}$ films could be a composite of amorphous carbide, amorphous carbon phases, and metallic chromium phases. The intensities of $\mathrm{D}$ and $\mathrm{G}$ decrease with the fraction of $\mathrm{C}_{2} \mathrm{H}_{2}$. However, the estimated $I_{\mathrm{D}} / I_{\mathrm{G}}$ values of four samples are close to each other, with a difference of less than $2 \%$, which means that the ratios of $s p 3$ and $s p 2$ bonds of the amorphous carbon phase of the four samples could be approximate. These results imply that the content of amorphous carbon phase decreases with the fraction of $\mathrm{C}_{2} \mathrm{H}_{2}$. A similar trend was also found in the direct current magnetron sputtering deposited $\mathrm{Cr}-\mathrm{C}$ films [24].

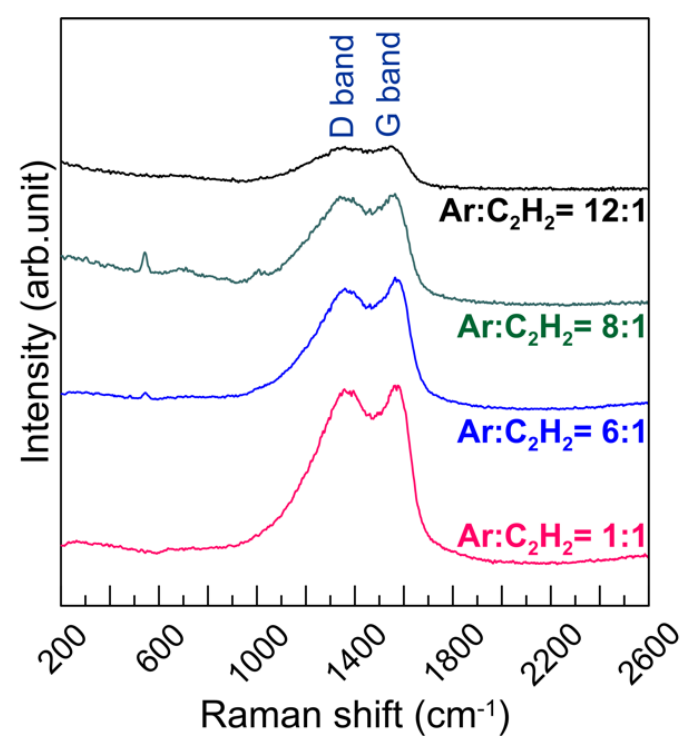

Figure 1. Raman spectra of $\mathrm{Cr}-\mathrm{C}$ films deposited on the AISI M35 high-speed steel with a substrate bias of $-60 \mathrm{~V}$ at a different $\mathrm{Ar} / \mathrm{C}_{2} \mathrm{H}_{2}$ mixture atmosphere, of $0.8 \mathrm{~Pa}$, for $10 \mathrm{~min}$.

The X-ray diffractograms of the $\mathrm{Cr}$ - $\mathrm{C}$ films deposited at different $\mathrm{Ar} / \mathrm{C}_{2} \mathrm{H}_{2}$ flow ratios are shown in Figure 2. There is no obvious diffraction peak in the diffractograms of films of $\mathrm{Ar} / \mathrm{C}_{2} \mathrm{H}_{2}$ flow ratios of 
1:1 and 6:1, which indicates that films deposited in this range of mixture ratio are amorphous or partial nanocrystalline. Weak peaks of $\alpha$-chromium and chromium carbide phases appeared in the films of $8: 1$, and the peak intensity of the $\alpha$-chromium phase became stronger in the film of $12: 1$. This indicates that the fraction of $\mathrm{C}_{2} \mathrm{H}_{2}$ may not be sufficient to react with the chromium species ejected from the target when the $\mathrm{Ar} / \mathrm{C}_{2} \mathrm{H}_{2}$ flow ratio is higher than 8:1. The XRD results confirm the previous surmise about amorphous carbon and partly nanocrystalline carbide phases, which are similar to the reported $\mathrm{Cr}-\mathrm{C}$ films by using sputtering $[10,24,34]$. The intensity around $40^{\circ}$ slightly increases with decreasing $\mathrm{C}_{2} \mathrm{H}_{2}$. This trend is also similar to the dc magnetron sputtering deposited $\mathrm{Cr}-\mathrm{C}$ films [24].

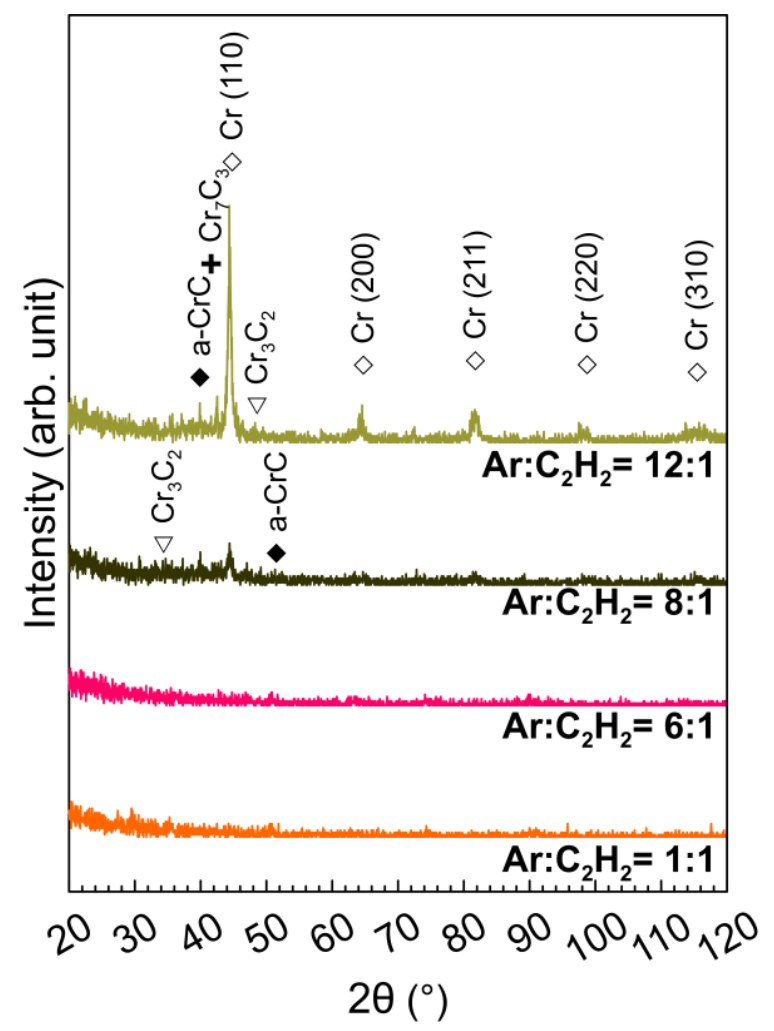

Figure 2. X-ray diffractograms of $\mathrm{Cr}-\mathrm{C}$ films deposited on the AISI M35 high-speed steel with a substrate bias of $-60 \mathrm{~V}$ at different $\mathrm{Ar} / \mathrm{C}_{2} \mathrm{H}_{2}$ mixture ratio atmosphere, of $0.8 \mathrm{~Pa}$, for $10 \mathrm{~min}$.

The top and cross-sectional SEM SE images of the $\mathrm{Cr}-\mathrm{C}$ films deposited at the pressure of $0.8 \mathrm{~Pa}$ with different $\mathrm{Ar} / \mathrm{C}_{2} \mathrm{H}_{2}$ flow ratios are shown in Figure 3. The film of 1:1 presents a loosen structure of stacking clusters, which is similar to the reported sputtering-deposited $\mathrm{Cr}-\mathrm{C}$ films with a high carbon content [10]. By increasing the fraction of argon, the film structure becomes denser and more columnar, without any granular edge, which is similar to the reported sputtering and HiPIMS-deposited Cr-C films with lower carbon contents [10,12]. These features of amorphous film are consistent with the results of XRD. The estimated deposition rates for $\mathrm{Ar} / \mathrm{C}_{2} \mathrm{H}_{2}$ ratios of 1:1, 6:1, 8:1, and 12:1 are 70, 153, 100 , and $122 \mathrm{~nm} / \mathrm{min}$, respectively. The partial pressure of argon with an $\mathrm{Ar} / \mathrm{C}_{2} \mathrm{H}_{2}$ ratio of 1:1 might be too low to sputter chromium atoms efficiently. On the other hand, the films of 1:1 and 6:1 were too fragile for hardness and adhesion tests. For these reasons, only the ratio of 8:1 were used in the following experiments of different substrate bias voltage and deposition temperature. The deposition time was also extended to $190 \mathrm{~min}$. 

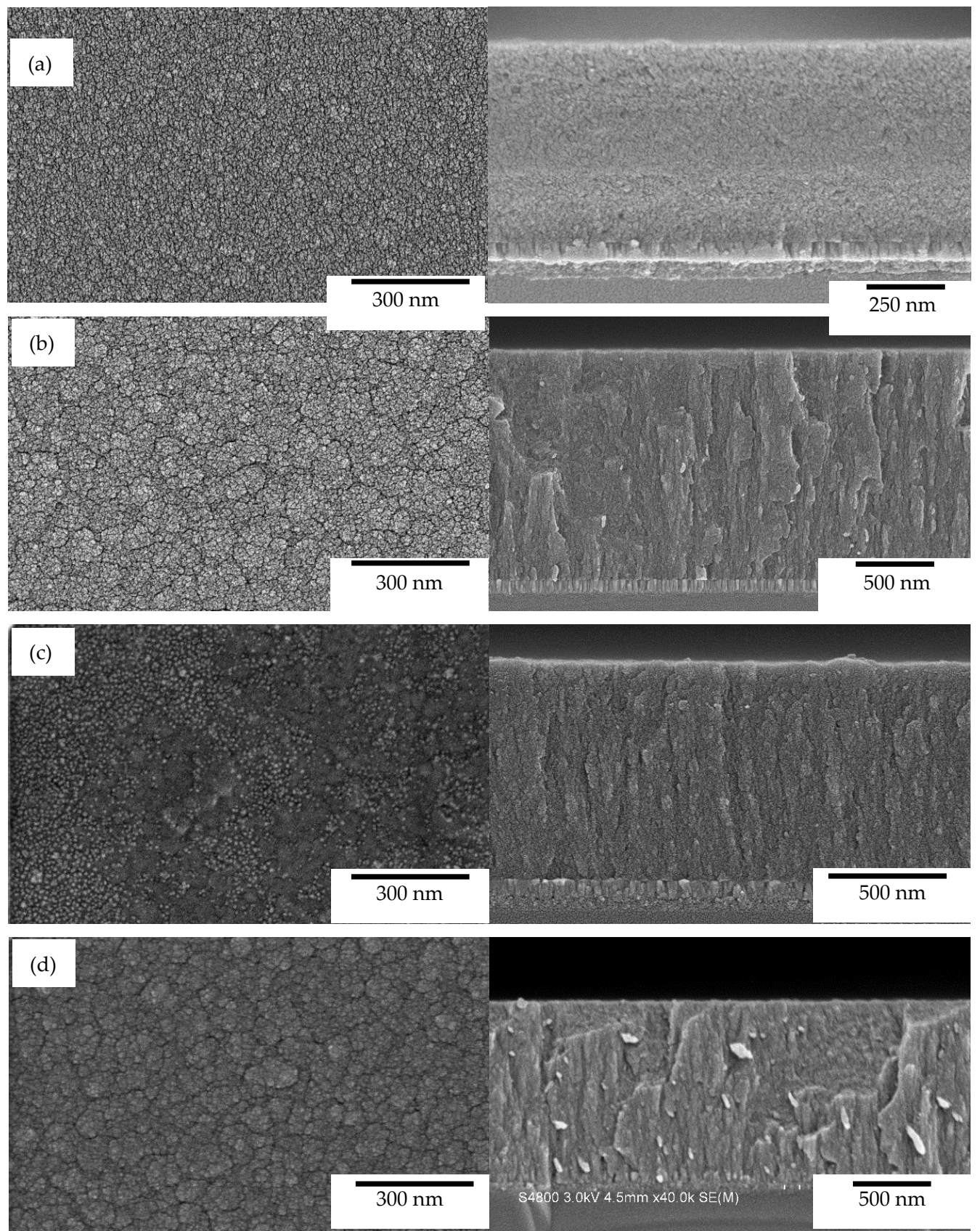

Figure 3. Top (left side) and cross-sectional (right side) SEM SE micrographs of $\mathrm{Cr}-\mathrm{C}$ films deposited at the deposition pressure of $0.8 \mathrm{~Pa}$ with the $\mathrm{Ar} / \mathrm{C}_{2} \mathrm{H}_{2}$ mixture ratio of (a) $1: 1$, (b) 6:1, (c) 8:1, and (d) 12:1 on a silicon wafer chip (substrate bias $-60 \mathrm{~V}$ ) for $10 \mathrm{~min}$.

\subsection{Influences of the Synchronized Substrate Bias and Deposition Temperature}

The X-ray diffractograms of the $\mathrm{Cr}-\mathrm{C}$ films deposited at the pressure $0.8 \mathrm{~Pa}$ with the same $\mathrm{Ar} / \mathrm{C}_{2} \mathrm{H}_{2}$ flow ratio, 8:1, but different substrate bias voltages are shown in Figure 4. All samples of the different substrate bias voltages are amorphous with minor $\alpha$-chromium phases. The intensity around $40^{\circ}$ is relatively stronger in films deposited with negative biases. A similar phenomenon was also found in $\mathrm{Cr}-\mathrm{C}$ films prepared by using vacuum arc [6,22], sputtering [12,23], and HiPIMS [12,18] depositions in an $\mathrm{Ar} /$ carbon hydride atmosphere. This suggests the formation of some nanocrystalline $\mathrm{CrC}$ with applying negative substrate bias due to the kinetic energy enhancement of incident ions [27-29]. A contrary phenomenon in Figure 4, which has never been reported in other similar researches, is that 
the intensity of the $\alpha$-chromium phase decreases by enhancing the substrate bias. Since the relative intensity of $\alpha$ (200) does not change, it is unlike the preferred orientation change resulting from the substrate biasing [31]. Besides, the $-60 \mathrm{~V}$ substrate bias is not strong enough to cause an obvious re-sputtering of light elements [22]. One possible reason is that the negative substrate bias promotes the formation of carbide phases [22], and therefore reduces the fraction of $\alpha$-chromium phases.

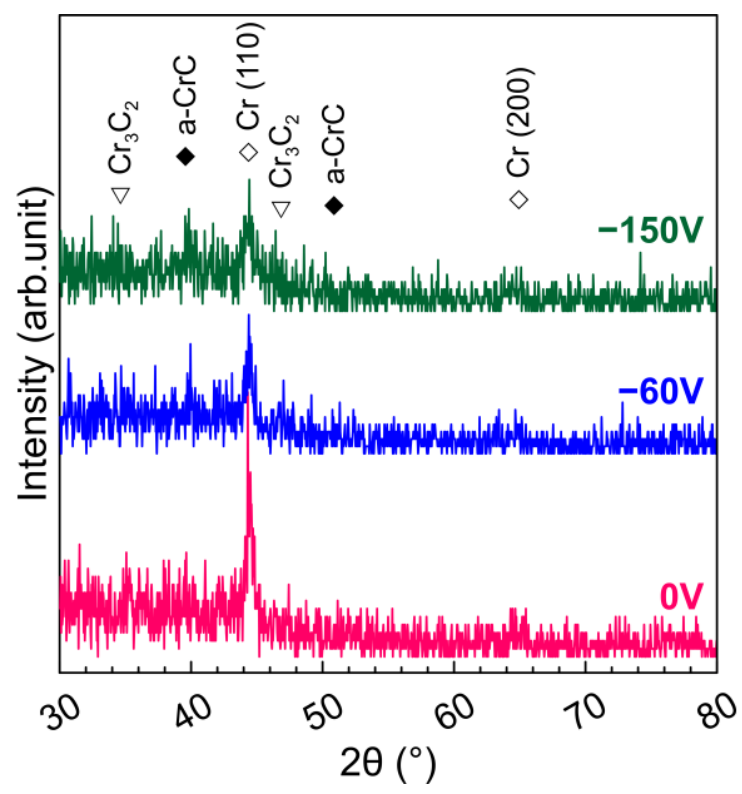

Figure 4. X-ray diffractograms of $\mathrm{Cr}$-C films deposited on the AISI M35 high-speed steel with different substrate bias voltages at the same atmosphere of $0.8 \mathrm{~Pa}$ and $\mathrm{Ar} / \mathrm{C}_{2} \mathrm{H}_{2}$ flow ratio of 8:1 for $190 \mathrm{~min}$.

The cross-sectional SEM SE images of the $\mathrm{Cr}-\mathrm{C}$ films deposited at the pressure of $0.8 \mathrm{~Pa}$ and the $\mathrm{Ar} / \mathrm{C}_{2} \mathrm{H}_{2}$ flow ratio 8:1 but with different synchronized substrate bias voltages are shown in Figure 5. The film becomes more solid, and the fracture surface becomes smoother and more brittle, with enhancing the negative substrate bias. This also evidences the increase of kinetic energy incident ions and adatoms to form a denser structure. The nanoindentation results of the $\mathrm{Cr}-\mathrm{C}$ film deposited with different substrate bias voltages shown in Figure 6 indirectly proves the densified film structure. The hardness of films increases by enhancing the negative substrate bias, which is similar to the results of vacuum arc deposited and the HiPIMS-deposited $\mathrm{Cr}-\mathrm{C}$ films $[6,12]$.

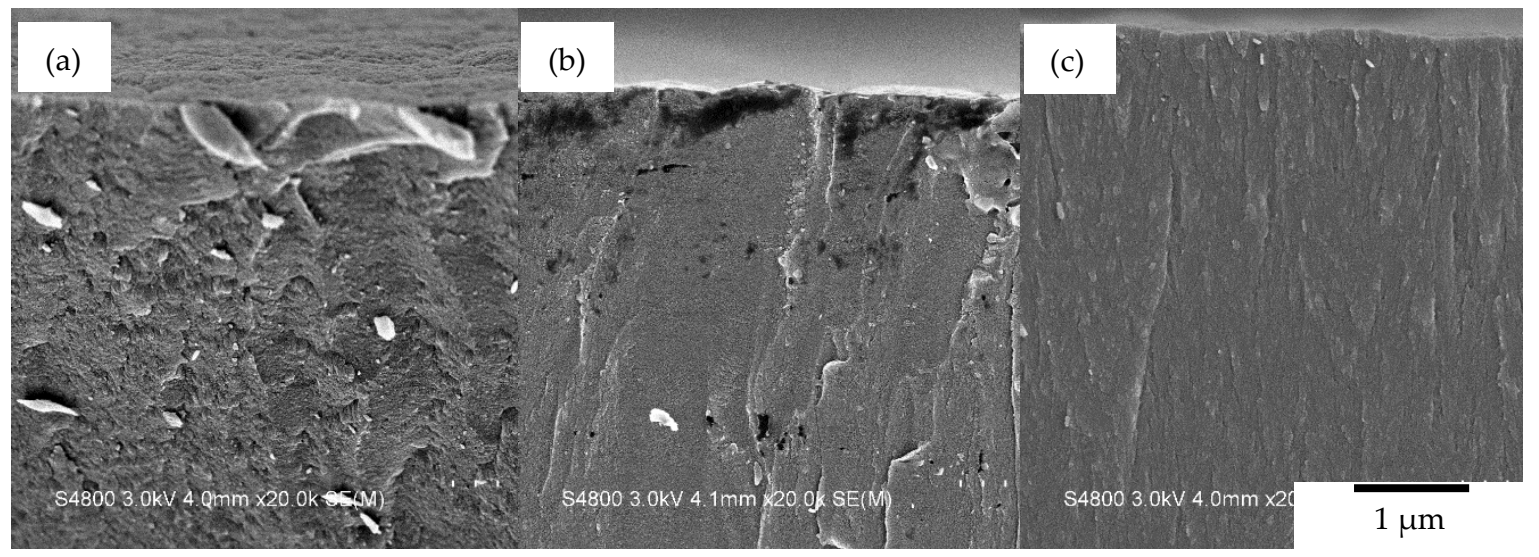

Figure 5. Cross-sectional SEM SE micrographs of $\mathrm{Cr}$ films deposited on a silicon wafer chip with the synchronized substrate bias voltage of (a) $0 \mathrm{~V},(\mathbf{b})-60 \mathrm{~V}$, and (c) $-150 \mathrm{~V}$, at the deposition pressure of $0.8 \mathrm{~Pa}$ with an $\mathrm{Ar} / \mathrm{C}_{2} \mathrm{H}_{2}$ mixture ratio of 8:1 for $190 \mathrm{~min}$. 


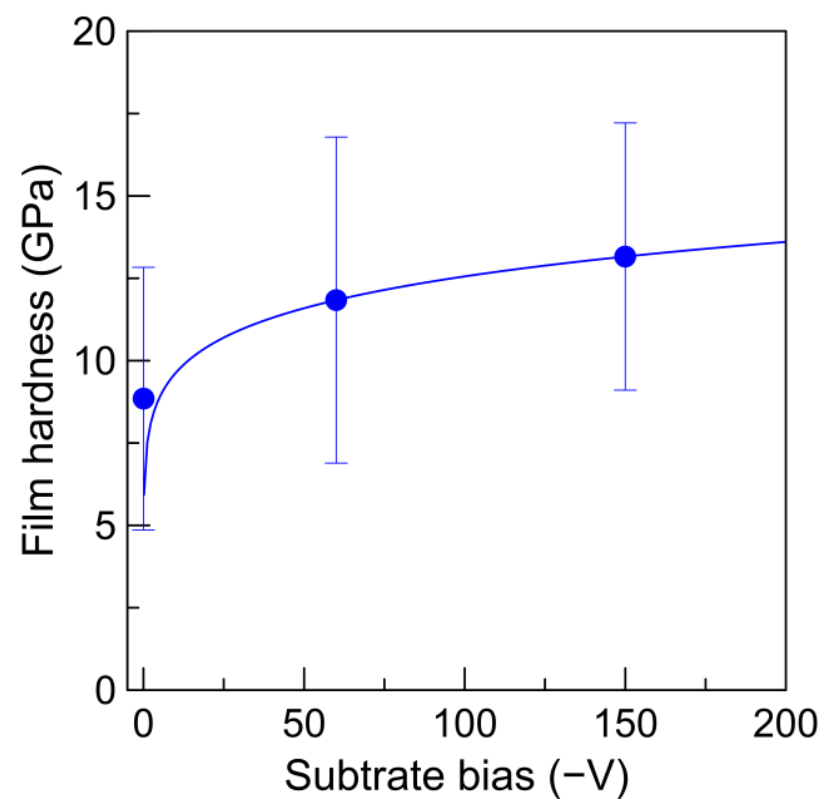

Figure 6. Film hardness versus the synchronized substrate bias voltage for $\mathrm{Cr}-\mathrm{C}$ films deposited on the AISI M35 high-speed steel at a pressure of $0.8 \mathrm{~Pa}$ and the $\mathrm{Ar} / \mathrm{C}_{2} \mathrm{H}_{2}$ mixture ratio of 8:1 for $190 \mathrm{~min}$.

Since most of the obtained films in this work are thinner than $2 \mu \mathrm{m}$, the indentations were carried out with a max load of $5 \mathrm{mN}$ and a 10-s pause to avoid the influences of substrate materials. The large measurement error could therefore be attributed to the microscale nonuniformity in the film structure. There are several phases, including a-Cr $\mathrm{Cr}_{y}, \mathrm{a}-\mathrm{C}: \mathrm{H}, \mathrm{Cr}, \mathrm{Cr}_{3} \mathrm{C}_{2}$, and droplets. The domain size of different phases could vary from several nanometers to a micrometer $[10,22,23]$. The reported hardness value of HiPIMS-deposited a-C:H could be higher than $30 \mathrm{GPa}$, and the hardness value of HiPIMS-deposited Cr could be lower than 7 GPa [12,18-20,31]. Such great difference between different phases might be the reason of the high measurement error.

The $\mathrm{Cr}-\mathrm{C}$ film deposited at $300^{\circ} \mathrm{C}$ and the same substrate bias of $-150 \mathrm{~V}$ in the same atmosphere present a cross-sectional microstructure similar to that of the film deposited at $200^{\circ} \mathrm{C}$. The hardness of the film deposited at $300{ }^{\circ} \mathrm{C}$ is $14.46 \pm 5.24 \mathrm{GPa}$, which is about $10 \%$ higher than the one at $200{ }^{\circ} \mathrm{C}$. The higher deposition temperature enables a higher mobility of adatoms, to form a denser and crystalline structure which usually results in more hardness. The $\mathrm{X}$-ray diffractograms of the $\mathrm{Cr}-\mathrm{C}$ films deposited at $200^{\circ} \mathrm{C}$ and $300^{\circ} \mathrm{C}$ are compared in Figure 7. Peaks of stoichiometric carbide phases slightly increase and peaks of amorphous carbide phase slightly weaken by raising the deposition temperature. This indicates that a higher temperature may promote the formation of stoichiometric carbide phases rather than an amorphous carbide phase. According to the Hall-Petch effect, the appearance of nanoscale grains may provide a grain boundary and strengthen the hardness of materials $[18,35]$. This could be one of the reasons for the higher hardness of $\mathrm{Cr}-\mathrm{C}$ films deposited at $300{ }^{\circ} \mathrm{C}$.

Deposition at a higher temperature is not recommended due to two reasons. One reason is that a higher temperature induces the conversion from hydrogenated amorphous carbon to nano-crystalline graphite [36], which usually results in the decrease of film hardness. Another reason depends on the heating method and consequent target conditions. The heating region should be restricted to the substrate. Heating the target surface should be avoided to minimize the target poisoning in such reactive sputtering [26]. In particular, the target for the HiPIMS process requires abundant cooling to release the heat generated by the high-density power input during the pulse on time. The carbides formed on the target surface due to poisoning are potential initiation points of the arc discharge and accompanying ejection of droplets during the high-power pulse on time. The droplets embedded in the $\mathrm{Cr}-\mathrm{C}$ films with a size of several micrometers are detrimental to the film uniformity, density, adhesion, and consequent performances. 


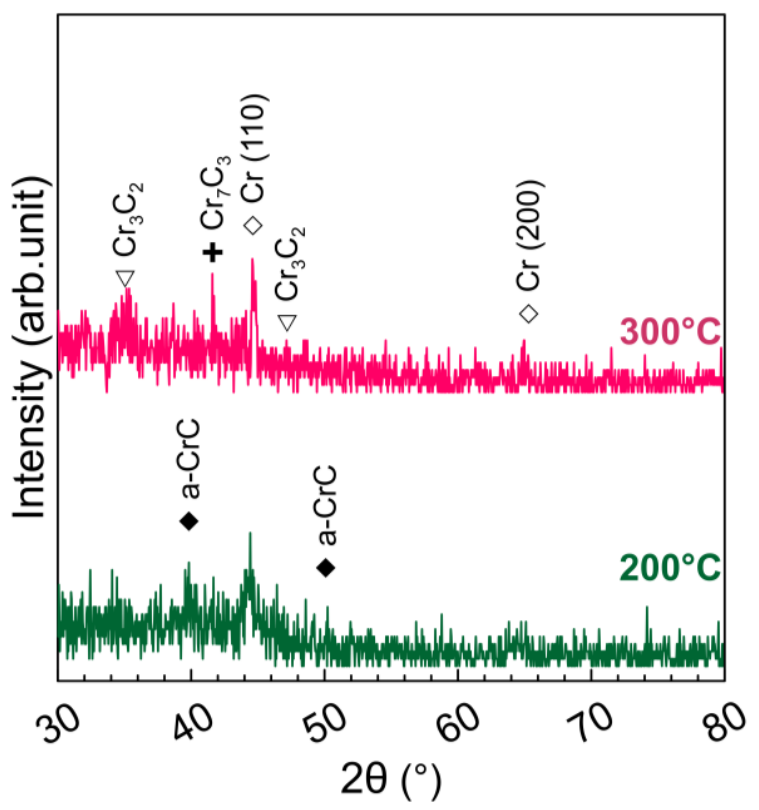

Figure 7. X-ray diffractograms of Cr-C films deposited on the AISI M35 high-speed steel at different deposition temperatures in the atmosphere of $0.8 \mathrm{~Pa}$ and $\mathrm{Ar} / \mathrm{C}_{2} \mathrm{H}_{2}$ mixture ratio of 8:1 with a substrate bias voltage of $-150 \mathrm{~V}$ for $190 \mathrm{~min}$.

The above results indicate that applying the reactive HiPIMS deposition to synthesized $\mathrm{Cr}-\mathrm{C}$ films can lead to a film structure, composition, and hardness similar to the one obtained by using direct current magnetron sputtering. Although the disadvantages of reactive direct current magnetron sputtering, such as the target poisoning and hysteresis, also occur in the reactive HiPIMS deposition, these can nevertheless be reduced by controlling the HiPIMS pulse frequency and duty cycle [26]. The results in this work indicate that applying the synchronized substrate bias can easily alter the film structure and film density at a relatively lower substrate temperature, due to the high ionization ratio in HiPIMS deposition.

\section{Conclusions}

This research preliminarily investigates the influences of reactive gas $\mathrm{C}_{2} \mathrm{H}_{2}$ ratio, synchronized substrate bias voltage, and deposition temperature on the $\mathrm{Cr}-\mathrm{C}$ films deposited by using reactive high-power impulse magnetron sputtering with the same average power, pulse frequency, and pulse duty cycle at a constant pressure of $0.8 \mathrm{~Pa}$. All the $\mathrm{Cr}-\mathrm{C}$ films obtained in this work are mainly amorphous. The films consists of amorphous or nanocrystalline chromium carbide, hydrogenated amorphous carbon, and a minor $\alpha$-chromium phase. Increasing the $\mathrm{Ar} / \mathrm{C}_{2} \mathrm{H}_{2}$ ratio increases the content of the $\alpha$-chromium phase but decreases the hydrogenated amorphous carbon phase. Increasing the $\mathrm{Ar} / \mathrm{C}_{2} \mathrm{H}_{2}$ ratio also promotes the film structure to change from loose stacking clusters into a solid columnar feature. Applying synchronized negative substrate bias also densifies the film structure and enhances the film hardness. Same enhancements can also be achieved by raising the substrate temperature, but not over $300^{\circ} \mathrm{C}$. The nanocrystallization of amorphous carbide phases promoted by negative substrate bias and substrate temperature induces the Hall-Petch strengthening effect and results in a higher film hardness.

Author Contributions: Conceptualization, C.-C.K.; data curation, C.-H.L.; investigation, J.-T.C., C.-H.L., and Y.-T.L.; methodology, C.-C.K. and C.-H.L.; project administration, C.-C.K.; supervision, C.-C.K.; visualization, J.-T.C. and C.-H.L.; writing-original draft, J.-T.C. and C.-C.K.; writing-review and editing, C.-C.K. All authors have read and agreed to the published version of the manuscript.

Funding: This research received no external funding. 
Acknowledgments: The authors wish to thank Supati Cooperation for their financial support. The Precision Instrument Support Center of Feng Chia University and Micro-Nano Technology Lab of National Formosa University are also acknowledged for the microstructure analysis instruments.

Conflicts of Interest: The authors declare no conflict of interest.

\section{References}

1. Komiya, S.; Ono, S.; Umezu, N.; Narusawa, T. Characterization of thick chromium-carbon and chromium-nitrogen films deposited by hollow cathode discharge. Thin Solid Films 1977, 45, 433-445. [CrossRef]

2. Toth, L.E. Transition Metal Carbides and Nitrides; Academic Press: New York, NY, USA, 1971; pp. 1-25.

3. Aubert, A.; Gillet, R.; Gaucher, A.; Terrat, J.P. Hard chrome coatings deposited by physical vapour deposition. Thin Solid Films 1983, 108, 165-172. [CrossRef]

4. Pierson, H.O. Handbook of Refractory Carbides and Nitrides, 1st ed.; Noyes Publications: New Jersey, NJ, USA, 1996; pp. 100-116.

5. Merl, D.K.; Panjan, P.; Čekada, M.; Maček, M. The corrosion behavior of Cr-(C,N) PVD hard coatings deposited on various substrates. Electrochim. Acta 2004, 49, 1527-1533. [CrossRef]

6. Lin, C.C.; Lee, J.W.; Chang, K.L.; Hsieh, W.J.; Wang, C.Y.; Chang, Y.A.; Shih, H.C. The effect of the substrate bias voltage on the mechanical and corrosion properties of chromium carbide thin films by filtered cathodic vacuum arc deposition. Surf. Coat. Technol. 2006, 200, 2679-2685. [CrossRef]

7. Edigaryan, A.A.; Safonov, V.A.; Lubnin, E.N.; Vykhodtseva, L.N.; Chusova, G.E.; Polukarov, Y.M. Properties and preparation of amorphous chromium carbide electroplates. Electrochim. Acta 2002, 47, 2775-2786. [CrossRef]

8. Chung, D.D.L. Carbon Composites: Composites with Carbon Fibers, Nanofibers and Nanotubes, 2nd ed.; Elsevier: Amsterdam, The Netherlands, 2017; pp. 387-466. [CrossRef]

9. Esteve, J.; Romero, J.; Go'mez, M.; Lousa, A. Cathodic chromium carbide coatings for molding die applications. Surf. Coat. Technol. 2004, 188-189, 506-510. [CrossRef]

10. Andersson, M.; Högström, J.; Urbonaite, S.; Furlan, A.; Nyholm, L.; Jansson, U. Deposition and characterization of magnetron sputtered amorphous Cr-C films. Vacuum 2012, 86, 1408-1416. [CrossRef]

11. Maréchal, N.; Quesnel, E.; Pauleau, Y. Deposition process and characterization of chromium-carbon coatings produced by direct sputtering of a magnetron chromium carbide target. J. Mater. Res. 1994, 9, 1820-1828. [CrossRef]

12. Nygren, K.; Samuelsson, M.; Flink, A.; Ljungcrantz, H.; Rudolphi, Å.K.; Jansson, U. Growth and characterization of chromium carbide films deposited by high rate reactive magnetron sputtering for electrical contact applications. Surf. Coat. Technol. 2014, 260, 326-334. [CrossRef]

13. Dai, W.; Wu, G.; Wang, A. Structure and elastic recovery of Cr-C:H films deposited by a reactive magnetron sputtering technique. Appl. Surf. Sci. 2010, 257, 244-248. [CrossRef]

14. Ziebert, C.; Ye, J.; Stüber, M.; Ulrich, S.; Edinger, M.; Barzen, I. Ion bombardment-induced nanocrystallization of magnetron-sputtered chromium carbide thin films. Surf. Coat. Technol. 2011, 205, 4844-4849. [CrossRef]

15. Gassner, G.; Mayrhofer, P.H.; Mitterer, C.; Kiefer, J. Structure-property relations in Cr-C/a-C:H coatings deposited by reactive magnetron sputtering. Surf. Coat. Technol. 2005, 200, 1147-1150. [CrossRef]

16. Poletika, I.M.; Ivanov, S.F.; Gnyusov, S.F.; Perovskaya, M.V. Electron-beam deposition of chromium carbide-based coatings with an ultradispersed structure or a nanostructure. Russ. Metall. 2016, 1275-1282. [CrossRef]

17. Wolfe, D.E.; Singh, J.; Narasimhan, K. Synthesis of titanium carbide/chromium carbide multilayers by the co-evaporation of multiple ingots by electron beam physical vapor deposition. Surf. Coat. Technol. 2002, 160, 206-218. [CrossRef]

18. Li, Z.-L.; Chen, Y.-Y.; Wang, C.-J.; Lee, J.-W. Comparison of chromium carbide thin films grown by different power supply systems. Surf. Coat. Technol. 2018, 353, 329-338. [CrossRef]

19. Konishi, T.; Yukimura, K.; Takaki, K. Fabrication of diamond-like carbon films using short-pulse HiPIMS. Surf. Coat. Technol. 2016, 286, 239-245. [CrossRef]

20. Tillmann, W.; Dias, N.F.L.; Stangier, D. Tribo-mechanical properties of CrC/a-C thin films sequentially deposited by HiPIMS and mfMS. Surf. Coat. Technol. 2018, 335, 173-180. [CrossRef] 
21. Richert, M.; Mazurkiewicz, A.; Smolik, J. Chromium carbide coatings obtained by the hybrid PVD methods. J. Achiev. Mater. Manuf. Eng. 2010, 43, 145-152.

22. Yate, L.; Martínez-de-Olcoz, L.; Esteve, J.; Lousa, A. Effect of the bias voltage on the structure of nc-CrC $x / \mathrm{a}-\mathrm{C}: \mathrm{H}$ coatings with high carbon content. Surf. Coat. Technol. 2012, 206, 2877-2883. [CrossRef]

23. Singh, V.; Jiang, J.C.; Meletis, E.I. Cr-diamond like carbon nanocomposite films: Synthesis, characterization and properties. Thin Solid Films 2005, 489, 150-158. [CrossRef]

24. Gassner, G.; Patscheider, J.; Mayrhofer, P.H.; Mitterer, C. Thermal stability of nanocomposite CrC/a-C:H thin films. Thin Solid Films 2007, 515, 5411-5417. [CrossRef]

25. Lundin, D.; Minea, T.; Gudmundsson, J.T. High Power Impulse Magnetron Sputtering: Fundamentals, Technologies, Challenges and Applications; Elsevier: Amsterdam, The Netherlands, 2019; ISBN 9780128124543.

26. Anders, A. Tutorial: Reactive high power impulse magnetron sputtering (R-HiPIMS). J. Appl. Phys. 2017, 121, 171101. [CrossRef]

27. Anders, A.; Andersson, J.; Ehiasarian, A. High power impulse magnetron sputtering: Current-voltage-time characteristics indicate the onset of sustained self-sputtering. J. Appl. Phys. 2007, 102, 113303. [CrossRef]

28. Kouznetsov, V.; Macak, K.; Schneider, J.; Helmersson, U.; Petrov, I. Hybrid HIPIMS and DC magnetron sputtering deposition of TiN coatings: Deposition rate, structure and tribological properties. Surf. Coat. Technol. 1999, 12, 290. [CrossRef]

29. Machunze, R.; Ehiasarian, A.; Tichelaar, F.; Janssen, G.; Ehiasarian, A. Stress and texture in HIPIMS TiN thin films. Thin Solid Films 2009, 518, 1561-1565. [CrossRef]

30. Kuo, C.C.; Lin, Y.T.; Chan, A.; Chang, J.T. High temperature wear behavior of titanium nitride coating deposited using high power impulse magnetron sputtering. Coatings 2019, 9, 555. [CrossRef]

31. Kuo, C.C.; Lin, C.H.; Lin, Y.T.; Chang, J.T. Effects of cathode voltage pulse width in high power impulse magnetron sputtering on the deposited chromium thin films. Coatings 2020, 10, 542. [CrossRef]

32. Greczynski, G.; Lu, J.; Jensen, J. Metal versus rare-gas ion irradiation during $\mathrm{Ti}_{1-x} \mathrm{Al}_{x} \mathrm{~N}$ film growth by hybrid high power pulsed magnetron/dc magnetron co-sputtering using synchronized pulsed substrate bias. J. Vac. Sci. Technol. 2012, 30, 061504. [CrossRef]

33. Cooke, K.E.; Hampshire, J.; Southall, W.; Teer, D.G. Industrial application of pulsed dc bias power supplies in closed field unbalanced magnetron sputter ion plating. Surf. Eng. 2004, 20, 189-195. [CrossRef]

34. Jellad, A.; Labdi, S.; Malibert, C.; Renou, G. Nanomechanical and nanowear properties of $\mathrm{Cr}_{3} \mathrm{C}_{2}$ thin films deposited by rf sputtering. Wear 2008, 264, 893-898. [CrossRef]

35. Guisbiers, G.; Herth, E.; Buchaillot, L.; Pardoen, T. Fracture toughness, hardness, and Young's modulus of tantalum nanocrystalline films. Appl. Phys. Lett. 2010, 97, 143115. [CrossRef]

36. Tallant, D.R.; Parmeter, J.E.; Siegal, M.P.; Simpson, R.L. The thermal stability of diamond-like carbon. Diam. Relat. Mater. 1995, 4, 191-199. [CrossRef]

Publisher's Note: MDPI stays neutral with regard to jurisdictional claims in published maps and institutional affiliations.

(C) 2020 by the authors. Licensee MDPI, Basel, Switzerland. This article is an open access article distributed under the terms and conditions of the Creative Commons Attribution (CC BY) license (http://creativecommons.org/licenses/by/4.0/). 